\title{
Assessment of pfcrt 72-76 haplotypes eight years after chloroquine withdrawal in Kinshasa, Democratic Republic of Congo
}

Dieudonné Makaba Mvumbi ${ }^{1 *}$, Raphael Boreux², Rosalie Sacheli ${ }^{2}$, Mvumbi Lelo ${ }^{1}$, Bobanga Lengu ${ }^{3}$, Situakibanza Nani-Tuma ${ }^{3}$, Pierrette Melin ${ }^{2}$, Kayembe Ntumba ${ }^{4}$, Kalala Lunganza', Patrick DeMol ${ }^{2}$ and Marie-Pierre Hayette ${ }^{2}$

\begin{abstract}
Background: In 2001, the World Health Organization (WHO) has recommended the use of artemisinin-based combination therapy (ACT) as the first-line treatment of uncomplicated malaria cases, as monotherapies had become ineffective in many parts of the world. As a result, the Democratic Republic of Congo (DRC) withdrew chloroquine (CQ) from its malaria treatment policy in 2002 and an artesunate (AS)-amodiaquine (AQ) combination became the ACT of choice in DRC in 2005. AQ-resistance (AQR) has been reported in several parts of the world and mutations in codons 72-76 of the Plasmodium falciparum chloroquine-resistance transporter (pfcrt) gene have been strongly correlated with resistance, especially mutations encoding the SVMNT haplotype. This haplotype was first identified in Southeast Asia and South America but was recently reported in two African countries neighbouring DRC. These facts raised two questions: the first about the evolution of CQ resistance (CQR) in DRC and the second about the presence of the SVMNT haplotype, which would compromise the use of $A Q$ as a partner drug for ACT.
\end{abstract}

Methods: A total of 213 thick blood films were randomly collected in 2010 from a paediatric clinic in Kinshasa, DRC. Microscopy controls and real-time polymerase chain reaction (RT-PCR) were performed for Plasmodium species identification. Haplotypes of the pfcrt gene were determined by sequencing.

Results: The K76T mutation was detected in 145 out of 198 P. falciparum-positive samples (73.2\%). In these 145 resistant strains, only the CVIET haplotype was detected.

Conclusions: This study is the first to assess the molecular markers of resistance to CQ and AQ after the introduction of ACT in DRC. The results suggest first that CQR is decreasing, as wild-type pfcrt haplotypes were found in only $26.8 \%$ of the samples and secondly that the SVMNT haplotype is not yet present in Kinshasa, suggesting that $A Q$ remains valid as a partner drug for $A C T$ in this region.

Keywords: Malaria, pfcrt, Drug resistance, RT-PCR, Sequencing, DR Congo

\footnotetext{
* Correspondence: didimvumbi@gmail.com

'Biochemistry and Molecular Biology Unit, Department of Basic Sciences, School of Medicine, University of Kinshasa, BP 190 KIN XI, Kinshasa, DR

Congo

Full list of author information is available at the end of the article
} reproduction in any medium, provided the original work is properly cited. The Creative Commons Public Domain Dedication waiver (http://creativecommons.org/publicdomain/zero/1.0/) applies to the data made available in this article, unless otherwise stated. 


\section{Background}

In 2001, the World Health Organization (WHO) has recommended the use of artemisinin-based combination therapy (ACT) as the first-line treatment of uncomplicated malaria cases because monotherapies had become ineffective in many parts of the world due to the spread of Plasmodium falciparum strains resistant to almost all anti-malarial drugs in use [1].

Resistance to chloroquine (CQ), the drug that had been widely used for decades for malaria treatment [2], has been well characterized and it is now established that a mutation (K76T) occurring in the P. falciparum chloroquine-resistance transporter ( $p f c r t$ ) gene is the key element [3-5]. Nevertheless many other mutations have been described in this gene [6].

Childs and colleagues were the first to show in vitro cross-resistance between amodiaquine (AQ) or its active metabolite and CQ [7]. Because of their pharmacological similarity, CQ and AQ were supposed to have the same molecular mechanism of resistance. Furthermore, Ochong et al., by analysing samples from a clinical trial held in southern Sudan, demonstrated a link between the K76T mutation and in vivo AQ resistance [8]. A few years later, other studies performed on the pfcrt gene revealed that some haplotypes defined by the aminoacids sequence at positions 72-76 of the CRT protein were related to a particular resistance profile and also to a specific geographical distribution. Sa et al. analysed reference strains and provided the first in vitro evidence that one of these haplotypes, the SVMNT (Ser-Val-Met-Asn-Thr), was strongly correlated with resistance to desethylamodiaquine (DEAQ), the active metabolite of AQ [9]. One year later, in vivo evidence of this link has been given by Beshir et al. who found that the presence of the SVMNT haplotype was sufficient to confer AQ resistance [10].

This haplotype was initially discovered in Asia and in South America [11,12], but it has recently been found in two African countries: first in Tanzania in 2006 [13], then in 2010 in Angola [14]. Both countries border the Democratic Republic of Congo (DRC), where CQ, after being widely used, was officially abandoned in 2002 to be replaced first by sulphadoxine-pyrimethamine (SP) and then by an artesunate-amodiaquine (AS-AQ) combination in 2005 [15].

This raised questions about the presence of the SVMNT haplotype in the DRC, which would jeopardize the use of $\mathrm{AQ}$ as a partner drug for ACT. These questions were addressed in this study.

\section{Methods}

\section{Sample collection}

A total of 213 thin and thick blood films (TBF) were randomly selected in April 2010 from the laboratory archives of the St Marc Paediatric Clinic of Masina (Kinshasa). All the smears were positive using microscopic recordings as selection criteria. The blood samples had been collected between January and March 2010 from children under five years who were suspected of malaria.

\section{Malaria diagnosis}

All blood smears underwent microscopic control performed by two experienced microscopists and the results were confirmed by real-time polymerase chain reaction (RT-PCR).

\section{DNA extraction}

The whole TBF was used for DNA extraction, leaving the thin smear for microscopic reading. Each TBF was first immersed in xylene for $10 \mathrm{~s}$ to avoid contamination between samples and to dissolve any residual oil from previous microscopic examinations. Then it was scratched out with a sterile scalpel as described previously by Cnops et al. [16]. The scraped material was transferred into a $1.5 \mathrm{ml}$ sterile Eppendorf tube containing $100 \mu \mathrm{l}$ of PBS and then used as a template for a semi-automated extraction using the Maxwell ${ }^{\circ} 16$ Cell LEV DNA purification Kit (Promega, USA). A DNA internal extraction and inhibition control was used to follow the extraction procedure (DIAcontrolDNA ${ }^{\oplus}$, Diagenode, Belgium). DNA was stored at $-20^{\circ} \mathrm{C}$ before processing.

\section{Real-time PCR}

The RT-PCR method for Plasmodium sp. identification was used as previously described [17]. Briefly, a fourprimer PCR was used in two duplex reactions including a couple of forward primers (Pfal + Pviv and Pmal + Pova) with a universal reverse primer (plasmo2). The probes and primers were designed to detect genes of the small subunit $18 \mathrm{~S}$ rRNA of Plasmodium species (Table 1). The mix consisted of: $12.5 \mu \mathrm{l}$ of $2 \mathrm{X}$ Taqman Universal PCR Master Mix (Applied Biosystems, USA), $200 \mathrm{nM}$ of all primers and probes except $P$. vivax at $100 \mathrm{nM}$ (primers and probe), $2.5 \mu \mathrm{l}$ of Internal Control primers and probes and the rest of water to make a total volume of $25 \mu \mathrm{l}$ including $5 \mu \mathrm{l}$ of DNA. PCR tests were run on a 7500 Fast Instrument (Applied Biosystems) and in the presence of positive controls (provided by the Parasitology Unit, Institute of Tropical Medicine, Antwerp and the Laboratory of Clinical Microbiology, University Hospital of Liège). PCR conditions were as follows: $2 \mathrm{~min}$ at $95^{\circ} \mathrm{C}$, followed by 50 cycles of $15 \mathrm{~s}$ at $95^{\circ} \mathrm{C}$ and $60 \mathrm{~s}$ at $60^{\circ} \mathrm{C}$.

\section{Pfcrt genotyping}

The procedure previously described by Ménard et al. [18] was modified by adding an M13 fragment on the 5' ends of the pfcrt primers (Table 1) to amplify a $154 \mathrm{bp}$ fragment that included the pfcrt codons in positions 72 76 of all of the P. falciparum-positive samples. PCR tests 
Table 1 Primer and probe sequences

\begin{tabular}{|c|c|c|c|}
\hline RT-PCR & Forward primer (plasmo1) & Reverse primer (plasmo2) & Probes \\
\hline Pfal & 5'-CTAGGTGTTGGATG-3' & 5'-TTATGAGAAATCAAAGTCTITGGGTT-3' & $\begin{array}{l}\text { 5'-FAM-AGCAATCTAAAAGTCACCT } \\
\text { CGAAAGATGACT-DQ-3' }\end{array}$ \\
\hline Pova & 5'-CGACTAGGTITTGGATG-3' & & 5'-VIC-CGAAAGGAATTITCTTATT-DQ-3' \\
\hline Pviv & 5'-GACTAGGCTTTGGATG-3' & & $\begin{array}{l}\text { 5'-VIC-AGCAATCTAAGAATAAACTCCG } \\
\text { AAGAGAAAATTCT-DQ-3' }\end{array}$ \\
\hline Pmal & 5'-GACTAGGTGTTGGATG-3' & & 5'-FAM-CTATCTAAAAGAAACACTCAT-DQ-3' \\
\hline PCR/genotyping & Forward primer & Reverse primer & \\
\hline Pfcrt & 5'-GTTCTTGTCTTGGTAAATGTGCTCA-3' & 5'-CAATT TTGTTTAAAGTTCTITAAGCAA-3' & \\
\hline
\end{tabular}

Legend: Pfal: P. falciparum; Pova: P.ovale; Pviv: P. vivax; Pmal: P. malariae; DQ: Darkquencher.

were run on a Hybaid PX2 (ThermoFischer Scientific, USA) under the following conditions: $95^{\circ} \mathrm{C}$ for $10 \mathrm{~min}$, followed by 45 cycles of $20 \mathrm{~s}$ at $95^{\circ} \mathrm{C}$ and $45 \mathrm{~s}$ at $60^{\circ} \mathrm{C}$. Amplification was controlled on a microchip electrophoresis system using the MCE-202 MultiNA (Shimadzu). Amplicons were purified on Sciclone G3 Automated Liquid Handling Workstation (Perkin Elmer, USA) using AgencourtCleanSEQ ${ }^{\circ}$ kit (Agencourt Bioscience, USA).

Sequencing was performed on a $3130 x l$ DNA sequencer (Applied Biosystems, USA).

Sequences were aligned using the GeneStudioTM ${ }^{\odot}$ Professional software and were compared with the reference sequence of the CRT protein [GenBank: CAD50842.1] using the online BLASTx tool.

\section{Ethical considerations}

This study has received the ethical approbation of the Ministry of Public Health of the DRC and of the Institutional Committee of the Faculty of Medicine, University of Kinshasa.

\section{Results}

Malaria diagnosis confirmation

RT-PCR lead to the detection of 202/213 (93.4\%) positive samples for $P$. falciparum including three mixed infections (P. falciparum + Plasmodium malariae).

\section{Pfcrt haplotypes}

Pfcrt genotyping was successfully performed for 198 $P$. falciparum samples from the 202 positive samples detected by RT-PCR. Among them, 145 K76T mutants (73.2\%) were detected and they were all harbouring the CVIET haplotype. The wild strains had the CVMNK haplotype. No other haplotypes were detected.

\section{Discussion}

Nearly ten years after the withdrawal of CQ in the firstline treatment of malaria in the DRC, CQR strains remain above the warning threshold established by WHO. However the prevalence of pfcrt $76 \mathrm{~T}$ mutants continues to decline as shown in previous studies performed in DR
Congo where a slow reversion in sensitivity has been recorded. Indeed, the percentage of Pf resistant strains went from $100 \%$ in 2000 [19], to $93 \%$ in 2002 [20], $83.8 \%$ in 2008 [21] and $73.2 \%$ in the present study. Finally, over the last ten years, the prevalence of resistant strains has decreased by $26.8 \%$. In other countries however, the decrease was much more significant like in Malawi where CQR fell from $85 \%$ to $13 \%$ in 8 years [22] after replacing CQ by SP or in Gabon with a drop of $55 \%(100 \%$ to $45 \%)$ in 6 years [23]. This fact could be explained by the large area covered by DRC that is more difficult to control, and by the relatively high cost of ACT compared to former monotherapies, resulting in a slower anti-malarial policy shift. Until 2007, CQ was still the most widely used anti-malarial drug in the DRC [24] although it was officially removed since 2002 and firstly replaced by SP. Aside from the efficiency with which new drug policies were implemented, malaria transmission intensity in the region and the use of many other anti-malarial drugs in addition to the national policy have been suggested to explain the difference in trend [25].

The CVIET haplotype was the only resistant haplotype identified in the present study. Indeed, it is the most prevalent haplotype among the five discovered to date in Africa and it seems that it has migrated from Southeast Asia to Africa via India [26,27]. Some studies have described this haplotype as a necessary but insufficient condition to confer AQ resistance [28,29]. Beshir et al. suggested that if the CVIET haplotype is highly prevalent, AQ can still be effective and further mutations on the $P$. falciparum multidrug resistance gene $(p f m d r 1)$ are required for the development of clinically significant $A Q$ resistance [10].

The only existing results on 72-76 pfcrt haplotypes that are available for the DRC refer to samples collected in 2000. The study identified $100 \%$ of resistant strains and these were distributed as follows: $14 / 27$ (51.8\%) SVIET, 12/27 (44.4\%) CVIET and 1/27 (3.7\%) of CVMNT [18]. Studies on a larger scale should be more representative of the high prevalence of the SVIET haplotype, which 
appears to be rare elsewhere in the world. In fact, it was found before only once, in a study performed in Papua New Guinea [30].

Our results showed that the SVMNT haplotype is not yet present in Kinshasa suggesting that $A Q$ remains valid as a partner drug for ACT. However, continuous monitoring is necessary because, initially absent from Africa, the SVMNT haplotype suddenly appeared in Tanzania in 2004, where it was not present the year before [13]. This fact shows how the emergence of a new haplotype can be spontaneous. This haplotype has been also found recently in Angola by Gama et al. who supposed that this haplotype may have been imported from Brazil [14]. Frosch et al. showed that Angola and Tanzania were among African countries where AQ was more extensively used than in other countries during the last decade [31]. This fact could have contributed to the selection of SVMNT resistant strains, as suggested by Sa and by others, who stipulated that AQ had a prominent role in the selection of parasites carrying the SVMNT haplotype $[10,13,32,33]$. In fact, SVMNT haplotype is predominant in countries where AQ was early and widely used [32].

Malaria is a disease of great geographical diversity and, as DRC is a very large country, the results of this study concern only the region of Kinshasa and further studies are needed.

\section{Conclusion}

This study confirms the slow reverse in sensitivity to CQ in Kinshasa. This is the first to assess resistance to AQ through pfcrt haplotypes after CQ withdrawal, especially based on TBFs. AQ remains effective as a partner molecule for ACT in Kinshasa but monitoring of $P$. falciparum genomic resistance is mandatory.

\section{Abbreviations}

ACT: Artemisinin-based combination therapy; AQ: Amodiaquine; AS: Artesunate; CQ: Chloroquine; DNA: Deoxyribonucleic acid; DRC: Democratic Republic of Congo; RT-PCR: Real-time polymerase chain reaction; SP: Sulphadoxine-pyrimethamine; TBF: Thick blood film; WHO: World health organization.

\section{Competing interests}

The authors declare that they have no competing interest

\section{Authors' contributions}

MMD collected samples, carried out the DNA extraction, performed RT-PCR analysis and drafted the manuscript. RB and RS supervised genotyping analysis. $\mathrm{ML}, \mathrm{KL}$ and SN conceived and designed the study protocol. BL participated in collecting samples. PM provided materials. MPH, KN and PDM supervised the study. All authors read and approved the manuscript.

\section{Acknowledgements}

The authors thank the Molecular Biology Unit of the University Hospital of Liège, Belgium.

This work was supported by the Coopération Universitaire pour le Développement (CUD)/Belgium.

\section{Author details}

${ }^{1}$ Biochemistry and Molecular Biology Unit, Department of Basic Sciences, School of Medicine, University of Kinshasa, BP 190 KIN XI, Kinshasa, DR Congo. ${ }^{2}$ Department of Clinical Microbiology, University Hospital of Liège, Liège, Belgium. ${ }^{3}$ Department of Tropical Medicine and Infectious Disease, School of Medicine, University of Kinshasa, Kinshasa, DR Congo. ${ }^{4}$ Department of Internal Medicine, School of Medicine, University of Kinshasa, Kinshasa, DR Congo.

Received: 16 September 2013 Accepted: 4 December 2013

Published: 20 December 2013

\section{References}

1. World Health Organization: Antimalarial drug combination therapy. Report of a WHO technical consultation. Geneva: WHO; 2001.

2. Wellems TE: Plasmodium chloroquine resistance and the search for a replacement antimalarial drug. Science 2002, 298:124-126.

3. Fidock DA, Nomura T, Talley AK, Cooper RA, Dzekunov SM, Ferdig MT, Ursos LM, Sidhu AB, Naude B, Deitsch KW, Su XZ, Wootton JC, Roepe PD, Wellems TE: Mutations in the $P$. falciparum digestive vacuole transmembrane protein PfCRT and evidence for their role in chloroquine resistance. Mol Cell 2000, 6:861-871.

4. Sidhu AB, Verdier-Pinard D, Fidock DA: Chloroquine resistance in Plasmodium falciparum malaria parasites conferred by pfcrt mutations. Science 2002, 298:210-213.

5. Djimde A, Doumbo OK, Cortese JF, Kayentao K, Doumbo S, Diourte $Y$, Dicko A, Su X-Z, Noruma T, Fidock DA, Wellems TE, Plowe CV: A molecular marker for chloroquine resistant falciparum malaria. N Engl J Med 2001, 344:257-263.

6. Chen N, Kyle DE, Pasay C, Fowler EV, Baker J, Peters JM, Cheng Q: pfcrt Allelic types with two novel amino acid mutations in chloroquine resistant Plasmodium falciparum isolates from the Philippines. Antimicrob Agents Chemother 2003, 47:3500-3505.

7. Childs GE, Boudreau EF, Milhous WK, Wimonwattratee T, Pooyindee N, Pang $L$, Davidson DE Jr: A comparison of the in vitro activities of amodiaquine and desethylamodiaquine against isolates of Plasmodium falciparum. Am J Trop Med Hyg 1989, 40:7-11.

8. Ochong EO, van den Broek IV, Keus K, Nzila A: Short report: association between chloroquine and amodiaquine resistance and allelic variation in the Plasmodium falciparum multiple drug resistance 1 gene and the chloroquine resistance transporter gene in isolates from the upper Nile in southern Sudan. Am J Trop Med Hyg 2003, 69:184-187.

9. Sa JM, Twu O, Hayton K, Reyes S, Fay MP, Ringwald P, Wellems TE: Geographic patterns of Plasmodium falciparum drug resistance distinguished by differential responses to amodiaquine and chloroquine. Proc Natl Acad Sci U S A 2009, 106:18883-18889.

10. Beshir K, Sutherland CJ, Merinopoulos I, Durrani N, Leslie T, Rowland M, Hallett RL: Amodiaquine resistance in Plasmodium falciparum malaria in Afghanistan is associated with the pfcrt SVMNT allele at codons 72 to 76. Antimicrob Agents Hemother 2010, 54:3714-3716.

11. Wootton JC, Feng X, Ferdig MT, Cooper RA, Mu J, Baruch DI, Magill AJ, Su XZ: Genetic diversity and chloroquine selective sweeps in Plasmodium falciparum. Nature 2002, 418:320-323.

12. Mehlotra RK, Fujioka H, Roepe PD, Janneh O, Ursos LMB, Jacobs-Lorena $V$, McNamara DT, Bockarie MJ, Kazura JW, Kyle DE, Fidock DA, Zimmerman PA: Evolution of a unique Plasmodium falciparum chloroquine-resistance phenotype in association with Pfcrt polymorphism in Papua New Guinea and South America. Proc Natl Acad Sci U S A 2001, 98:12689-12694.

13. Alifrangis M, Dalgaard MB, Lusingu JP, Vestergaard LS, Staalsoe T, Jensen AT, Enevold A, Ronn AM, Khalil IF, Warhurst DC, Lemnge MM, Theander TG, Bygbjerg IC: Occurrence of the Southeast Asian/South American SVMNT haplotype of the chloroquine-resistance transporter gene in Plasmodium falciparum in Tanzania. J Infect Dis 2006, 193:1738-1741.

14. Gama BE, de Carvalho GA P, LutucutaKosi FJ, de Oliveira NK A, Fortes F, Rosenthal PJ, Daniel Ribeiro CT, da Cruz MD F: Plasmodium falciparum isolates from Angola show the SVMNT haplotype in the pfcrt gene. Malar J 2010, 9:174.

15. Kazadi WM, Vong S, Makina BN, Mantshumba JC, Kabuya W, Kebela B, Ngimbi NP: Assessing the efficacy of chloroquine and sulfadoxine-pyrimethamine for treatment of uncomplicated Plasmodium falciparum malaria in the Democratic Republic of Congo. Trop Med Int Health 2003, 8:868-875. 
16. Cnops L, Van Esbroeck M, Bottieau E, Jacobs J: Giemsa-stained thick blood films as a source of DNA for Plasmodium species-specific real-time PCR. Malar J 2010, 9:370.

17. Cnops L, Jacobs J, Van Esbroeck M: Validation of a four-primer real-time PCR as a diagnostic tool for single and mixed Plasmodium infections. Clin Microbiol Infect 2011, 17:1101-1107.

18. Menard S, Morlais I, Tahar R, Sayang C, IssamouMayengue P, Iriart X, Benoit-Vical F, Lemen B, Magnaval J-F, Awono-Ambene P, Basco LK, Berry A: Molecular monitoring of Plasmodium falciparum drug susceptibility at the time of the introduction of artemisinin-based combination therapy in Yaoundé, Cameroon: implications for the future. Malar $J$ 2012, 11:113.

19. Severini C, Menegon M, Sannella AR, Paglia MG, Narciso P, Matteelli A, Gulletta M, Caramello P, Canta F, Xayavong MV, Moura IN, Pieniazek NJ, Taramelli D, Majori G: Prevalence of pfcrt point mutations and level of chloroquine resistance in Plasmodium falciparum isolates from Africa. Infect Genet Evol 2006, 6:262-268.

20. Wilson PE, Kazadi W, Kamwendo DD, Mwapasa V, Purfield A, Meshnick SR: Prevalence of pfcrt mutations in Congolese and Malawian Plasmodium falciparum isolates as determined by a new Taqman assay. Acta Trop 2005, 93:97-106.

21. Mobula L, Lilley B, Tshefu AK, Rosenthal PJ: Resistance-mediating Polymorphisms in Plasmodium falciparum infections in Kinshasa, Democratic Republic of the Congo. Am J Trop Med Hyg 2009, 80:555-558.

22. Kublin JG, Cortese JF, Njunju EM, Mukadam RA, Wirima JJ, Kazembe PN, Djimdé AA, Kouriba B, Taylor TE, Plowe CV: Reemergence of chloroquinesensitive Plasmodium falciparum malaria after cessation of chloroquine in Malawi. J Infect Dis 2003, 187:1870-1875.

23. Schwenke A, Brandts C, Philipps J, Winkler S, Wernsdorfer WH, Kremsner PG: Declining chloroquine resistance of Plasmodium falciparum in Lambarene, Gabon from 1992 to 1998. Wien Klin Wochenschr 2001, 113:63-64.

24. MeasureDHS, ICF Macro: [http://www.measuredhs.com] EDS RDC 2007

25. Gharbi M, Flegg JA, Hubert V, Kendjo E, Metcalf JE, Bertaux L, Guérin PJ, Le Bras J, Members of the French National Reference Centre for Imported Malaria Study: Longitudinal study assessing the return of chloroquine susceptibility of Plasmodium falciparum in isolates from travellers returning from West and Central Africa, 2000-2011. Malar J 2013, 12:35.

26. Awasthi G, Prasad GBKS, Das A: Population genetic analyses of Plasmodium falciparum chloroquine receptor transporter gene haplotypes reveal the evolutionary history of chloroquine-resistant malaria in India. Int J Parasitol 2011, 41:705-709.

27. Anderson TJ, Nair S, Qin H, Singlam S, Brockman A, Paiphun L, Nosten F: Are transporter genes other than the chloroquine resistance locus ( $p f c r t$ ) and multidrug resistance gene ( $p f m d r$ ) associated with antimalarial drug resistance? Antimicrob Agents Chemother 2005, 49:2180-2188.

28. Holmgren GJ, Hamrin J, Svard J, Mårtensson A, Gil JP, Bjorkman A: Selection of pfmdr1 mutations after amodiaquine monotherapy and amodiaquine plus artemisinin combination therapy in East Africa. Infect Genet Evol 2007, 7:562-569.

29. Nsobya SL, Dokomajilar C, Joloba M, Dorsey G, Rosenthal PJ: Resistancemediating Plasmodium falciparum pfcrt and pfmdr1 alleles after treatment with artesunate-amodiaquine in Uganda. Antimicrob Agents Chemother 2007, 51:3023-3025.

30. Nagesha SH, Casey GJ, Rieckmann KH, Fryauff DJ, Laksana BS, Reeder JC, Maguire JD, Baird JK: New haplotypes of the Plasmodium falciparum chloroquine resistance transporter ( $p f c r t$ ) gene among chloroquineresistant parasite isolates. Am J Trop Med Hyg 2003, 68:398-402.

31. Frosch AEP, Venkatesan M, Laufer MK: Patterns of chloroquine use and resistance in sub-Saharan Africa: a systematic review of household survey and molecular data. Malar J 2011, 10:11.
32. Sa JM, Twu O: Protecting the malaria drug arsenal: halting the rise and spread of amodiaquine resistance by monitoring the PfCRT SVMNT type. Malar J 2010, 9:374.

33. Folarin OA, Bustamante C, Gbotosho GO, Sowunmi A, Zalis MG, Oduola AMJ, Happi CT: In vitro amodiaquine resistance and its association with mutations in pfcrt and pfmdr1 genes of Plasmodium falciparum isolates from Nigeria. Acta Trop 2011, 120:224-230.

doi:10.1186/1475-2875-12-459

Cite this article as: Mvumbi et al.: Assessment of pfort 72-76 haplotypes eight years after chloroquine withdrawal in Kinshasa,

Democratic Republic of Congo. Malaria Journal 2013 12:459.

\section{Submit your next manuscript to BioMed Central and take full advantage of:}

- Convenient online submission

- Thorough peer review

- No space constraints or color figure charges

- Immediate publication on acceptance

- Inclusion in PubMed, CAS, Scopus and Google Scholar

- Research which is freely available for redistribution

Submit your manuscript at www.biomedcentral.com/submit
C Biomed Central 